\title{
Carbide formation in tungsten-containing amorphous carbon films
}

\section{by annealing}

\author{
M. Balden ${ }^{1}$, P.A. Sauter ${ }^{1}$, S. Jong ${ }^{1}$, C. Adelhelm ${ }^{1}$, S. Lindig ${ }^{1}$, M. Rasinski ${ }^{1,2}$, T. Plocinski ${ }^{2}$ \\ ${ }^{1}$ Max-Planck-Institut für Plasmaphysik, EURATOM Association, Boltzmannstr. 2, 85748 Garching, Germany \\ ${ }^{2}$ Warsaw University of Technology, Faculty of Material Science and Engineering, Woloska 141, 02-507, \\ Poland
}

\begin{abstract}
Tungsten-containing amorphous carbon films were produced by dual magnetron sputter deposition. The formation of carbide phases after heat treatment in inert gas at temperatures up to $2800 \mathrm{~K}$ was investigated by X-ray diffraction for tungsten concentrations below $25 \mathrm{at} \%$. After deposition, each film consists of an amorphous carbon matrix with atomically dispersed W inclusions. Annealing up to $2800 \mathrm{~K}$ leads to a formation of carbide phases and to nano clustering. Three tungsten carbide phases were observed $\left(\mathrm{WC}, \mathrm{W}_{2} \mathrm{C}, \mathrm{WC}_{1-\mathrm{x}}\right)$, mostly as mixtures of two phases. The phase combination depends on annealing temperature and $\mathrm{W}$ concentration. Additionally, nano diffraction was performed in a scanning transmission electron microscope, to determine the phase of single crystallites at scales, where X-ray diffraction fails.
\end{abstract}

keywords: Plasma-Materials Interaction, Carbon-based amorphous films, Chemical Reactions

*Corresponding author e-mail: Philipp.Sauter@ipp.mpg.de

*Corresponding author address: Boltzmannstrasse 2, 85748 Garching, Germany

*Corresponding author phone: + 498932991923

*Corresponding author fax: + 498932991212 


\section{Introduction}

For the international thermonuclear experimental reactor (ITER), carbon (C), tungsten (W) and beryllium, are planned as plasma-facing material (PFM) [1]. A mixture of sputtered and eroded PFMs will form co-deposited layers that will grow linearly with time [2]. Especially their structural properties, influencing the interaction between plasma and PFM (erosion behaviour, tritium retention) [3], are in focus of our attention.

Nano-structured, metal-containing, amorphous carbon films (a-C:Me, $\mathrm{Me}=\mathrm{W}, \mathrm{Ti}, \mathrm{V}, \mathrm{Zr}$ ) produced by magnetron sputter deposition are used as model system to study the structure of metal containing co-deposited layers. Therefore, parameter studies (Me concentration, pre-heating temperature) are performed. The present investigation is embedded in a fundamental research on the influence of small amounts $(\leq 20$ at $\%)$ of nano-sized Me carbide inclusions on the structure of amorphous $\mathrm{C}$ films (carbide formation, change of the chemical bonding in the near vicinity of Me carbides and inside the carbon matrix [3]). Performing heat treatment on the deposited films carbide phases, which appear to be forbidden in thermo-dynamic equilibrium [4], have been achieved [3]. Therefore, structural properties are supposed to be adaptable on a certain demand of an application, beyond the scope of fusion research. a-C:Me films were intensively studied in the last years and have great importance for application as hard and wear resistant coatings [5-9]. Most frequently, the carbide forming metals (e.g.W used in this study) are used as dopant [10]. Improved tribological and mechanical properties compared to pure carbon films are achieved by a nanocomposite structure with nanometer-sized carbide particles in an amorphous carbon matrix. Such coatings are also investigated in respect with their improved optical and electrical properties $[11,12]$. 
So, basic knowledge on the phase formation is required especially for W-C systems which exhibit at least three carbide phases. In previous studies [3], X-ray diffraction (XRD) was performed on a $9 \% \mathrm{~W}$ containing a-C:W film, annealed up to $1300 \mathrm{~K}$. Even without annealing an intensive, broad peak can be observed around $37.4^{\circ}$. With annealing, the peak maximum shifts slightly to higher angles $\left(38.6^{\circ}\right.$ for $\left.1300 \mathrm{~K}\right)$, becomes more intensive and decreases in width. The FWHM reduces from $11.3^{\circ}$ (as-deposited) to $6.1^{\circ}(1300 \mathrm{~K})$. Two other peaks can be observed at 62 and $75^{\circ}$ for annealing to $\geq 1100 \mathrm{~K}$. A weak bump around $72^{\circ}$ is already visible for the diffractogram of the as-deposited sample. No texture was observed. Extended x-ray absorption fine structure studies showed that films are amorphous. In order to follow up this trend, annealing temperatures were increased up to $2800 \mathrm{~K}$. Further on, higher $\mathrm{W}$ concentrations (up to 22 at $\%$ ) were investigated, regarding their carbide formation by annealing.

\section{Experimental}

\section{1 a-C:W film deposition and heat treatment}

Thin a-C:W films were deposited by dual magnetron sputter deposition on pyrolytic graphite plates (polished with diamond paste and cleaned in ultrasonic bath) and on $\mathrm{Si}$ (100) wafer fragments, using a graphite and a tungsten cathode with argon sputtering gas. Two commercial multi magnetron sputter devices were used (Denton Vacuum Discovery 18, Leybold Unnex $450 \mathrm{C}$ ). The power at the graphite cathode was supplied by a RF generator (fixed at $500 \mathrm{~W}$ in the Denton sputter device and at $600 \mathrm{~W}$ in the Leybold device). The tungsten concentration $(\leq 22 \% \mathrm{~W})$ was set by selecting a power between $2 \mathrm{~W}$ and 20 
$\mathrm{W}$ for the DC discharge, in each device. Tungsten concentrations are given in atomic percent throughout the paper.

Tungsten concentrations and film thickness were determined by Rutherford backscattering spectrometry (RBS) with ${ }^{4} \mathrm{MeV} 4 \mathrm{He}$, in the Garching tandem accelerator facility. The film thickness varied between 0.3 and $3.8 \mu \mathrm{m}$. Small amounts of $\operatorname{Ar}(\leq 3$ at $\%)$ and $\mathrm{O}(\leq 3$ at $\%)$ impurities were detected.

Specimens with $6,7,9,18$ and $22 \%$ tungsten were selected for heat treatment. a-C:W films were annealed in He atmosphere for one hour at different temperatures $(1450 \mathrm{~K}, 1800 \mathrm{~K}$, $2200 \mathrm{~K}$ and $2800 \mathrm{~K})$.

\subsection{Analysis of phase transformations in the a-C:W system: XRD and STEM}

The crystallographic phase in a-C:W films were determined by XRD using a Seifert XRD 3003 PTS diffractometer operated with $\mathrm{Cu} \mathrm{Ka}$ radiation. The experimental setup was optimized to measure thin films. Details are described elsewhere [3]. The most spectra were acquired as theta-scans at a gracing incidence angle of $5^{\circ}$. Phases were identified comparing the peak position in the X-ray diffractogram with peak positions of $\mathrm{W}$ carbide standards, tabulated in the ICDD data base as powder diffraction files (PDF) [13]. The Scherrer formula with a pre-factor of 1 was used for an estimation of the carbide crystallite size D [14]

$$
\mathrm{D}=\frac{\lambda}{\mathrm{B}_{2 \theta} \cdot \cos \theta_{\mathrm{B}}}
$$

with $\mathrm{B}_{2 \theta}$ the peak FWHM, $\theta_{\mathrm{B}}$ the peak position and $\lambda$ the radiation wavelength $(0.154 \mathrm{~nm})$. 
Peak broadening is assumed to be dominated by the small crystallite size and the experimental line width is neglected.

The surface morphology was investigated in a scanning electron microscope (SEM) [Helios Nanolab 600, FEI]. Film growth and the depth distribution of crystallite sizes was visualized by cross-section SEM with focused ion beam (Helios Nanolab 600, FEI). Another focused ion beam microscope from Warsaw University was used for the preparation of lamella. Argon ion milling in a Gentle Mill device was applied for final thinning and elimination of FIB defects.

Bright field and $\mathrm{Z}$ contrast imaging and nano diffraction was carried out on a $200 \mathrm{kV}$ ultra high resolution scanning transmission electron microscope UHR STEM microscope (Hitachi HD-2700) equipped with a $\mathrm{C}_{\mathrm{s}}$ corrector. Therefore it was possible to probe the structure of nano particles and to identify their phase.

\section{Results and discussion - W carbide phases}

A special focus was put on the attempt to observe the phase transformation from $\mathrm{W}_{2} \mathrm{C}$ to $\mathrm{WC}$, in the temperature range between $1450 \mathrm{~K}$ and $2800 \mathrm{~K}$, for the $9.5 \%$ a-C:W film $\left(\mathrm{W}_{2} \mathrm{C}\right.$ was proposed already at $1300 \mathrm{~K}$ and $\mathrm{WC}$ was observed at $1700 \mathrm{~K}$ [3]). Phases, textures and crystallite sizes were analysed by XRD. For comparison, nano diffraction was performed on $9 \%$ a-C:W samples, annealed to $1450 \mathrm{~K}$ and to $2800 \mathrm{~K}$. 


\subsection{X-ray diffraction}

The X-ray diffractograms for an annealing series of $9 \%$ a-C:W are shown in figure 1a). For the as-deposisted sample and samples annealed to temperatures below $2000 \mathrm{~K}$, no carbide phases are allocatable, since only broad peaks were observed in the diffractograms. There is no hint on a texture. Annealing to $2200 \mathrm{~K}$ leads to occurrence of peaks which can be attributed to the $\mathrm{WC}_{1-\mathrm{x}}$ phase. At $35^{\circ}$ a small shoulder appears at the peak position of the $\mathrm{W}_{2} \mathrm{C}$ standard. The $\mathrm{WC}_{1-\mathrm{x}}$ peak around $37^{\circ}$ shows a steep descent that levels out unexpected strongly at $39^{\circ}$, i.e. at another peak position of the $\mathrm{W}_{2} \mathrm{C}$ standard. This is a hint on the $\mathrm{W}_{2} \mathrm{C}$ phase. At $2800 \mathrm{~K}$ clearly a mixture of $\mathrm{WC}$ and $\mathrm{WC}_{1-\mathrm{x}}$ is present in the film. The peak at $34^{\circ}$ can be identified as $\mathrm{WO}_{3}$. $\mathrm{AWO}_{3}$ surface layer is supposed to be build up (see section 3.2). This may be caused by a leak at the furnace during the heating run at 2800 K.

Annealing the $6 \%$ and the $7 \% \mathrm{~W}$-containing specimens to $2200 \mathrm{~K}$ leads to an analogue carbide formation with $\mathrm{WC}_{1-\mathrm{x}}$ as a dominant phase (the diffractogram is not shown).

Figure 1b) shows the evolution of the diffraction patterns of a $18 \%$ a-C:W film. A broad bump around $35^{\circ}$ and around $70^{\circ}$ occurs only in the as-deposited sample. Already after annealing to $1450 \mathrm{~K}$ both the $\mathrm{WC}$ and the $\mathrm{W}_{2} \mathrm{C}$ phase exists. With increasing the annealing temperature the intensity for the $\mathrm{WC}$ peaks increases while for the $\mathrm{W}_{2} \mathrm{C}$ peaks decreases. After annealing at $2800 \mathrm{~K}$ the dominant phase is $\mathrm{WC}$. The $\mathrm{W}_{2} \mathrm{C}$ peaks disappeared. At $34^{\circ}$ again the $\mathrm{WO}_{3}$ peak is present, as already mentioned for the case of lower $\mathrm{W}$ concentrations. The diffraction patterns of the $22 \%$ a-C:W film are depicted in Figure 1c), for temperatures up to $2200 \mathrm{~K}$. At $1450 \mathrm{~K}$ the $\mathrm{WC}$ phase is clearly identified and no indication for $\mathrm{W}_{2} \mathrm{C}$ and $\mathrm{WC}_{1-\mathrm{x}}$ exists. With increasing temperature an overall increase in peak intensity and a peak 
narrowing is observed. This is due to growth in crystallite size $(>50 \mathrm{~nm})$ with increasing annealing temperature. For instance, the FWHM of the peak at $48^{\circ}$ decreases from $0.61^{\circ}$ at $1450 \mathrm{~K}$ to $0.19^{\circ}$ at $2200 \mathrm{~K}$. Crystallite sizes that are smaller than $20 \mathrm{~nm}$ at $1450 \mathrm{~K}$ increase to values larger than $50 \mathrm{~nm}$ at $2200 \mathrm{~K}$.

\subsection{Nano diffraction at individual crystallites}

For the $9 \%$ a-C:W sample, $\mathrm{WC}$ and $\mathrm{WC}_{1-\mathrm{x}}$ were clearly observed by $\mathrm{XRD}$ after annealing to $2800 \mathrm{~K}$. For comparison, nano diffraction was performed. Figure 2a) shows a SEM image of a cross-section of a $9 \%$ a-C:W sample annealed to $2800 \mathrm{~K}$. Two size types particles are visible (large crystallites: up to several hundred $\mathrm{nm}$ in size, small crystallites: 10-100 $\mathrm{nm}$ in size). Figure 2b) shows a STEM bright field image of a small crystallite, chosen for nano diffraction. The diffraction pattern of this crystallite (figure 2d) corresponds to the $\mathrm{WC}_{1-\mathrm{x}}$ phase. Some of the small crystallites, however, are present in the WC phase, too (figure 2c). Performing nano diffraction at the large particles the WC phase was found. Note the oxide layer at the surface (oxidised W carbide grains are irregularly shaped and light grey in figure $2 \mathrm{a}$ ).

For the as-deposited sample and for samples annealed to temperatures below $2000 \mathrm{~K}$, no carbide phases are allocatable in the diffractograms, since broad peaks were observed. Nano diffraction on a $9 \%$ a-C:W sample annealed to $1450 \mathrm{~K}$ was performed in order to learn, weather peak broadening is due to atomically dispersed $\mathrm{W}$ inclusions, phase mixtures or small distorted W carbide particles. Figure 3a) shows a STEM image of a cross-section of a $9 \%$ a-C:W sample annealed to $1450 \mathrm{~K}$. The film is built up in a columnar structure. Figure $3 b$ ) shows a magnification in nm-scale, in bright field mode. A part of this image 
(upper right corner) is depicted in Z-contrast. Atomar structures are visible, which allows an estimation of crystallite sizes $(1-5 \mathrm{~nm})$. Nano diffraction on single crystallites (figure 3c and $3 \mathrm{~d})$ clearly reveals the presence of two $\mathrm{W}$ carbide phases $\left(\mathrm{W}_{2} \mathrm{C}\right.$ and $\left.\mathrm{WC}_{1-\mathrm{x}}\right)$.

Figures $4 \mathrm{a}$ ) and $4 \mathrm{~b}$ ) show SEM images of cross-sections of a-C:W samples annealed to $2200 \mathrm{~K}$, with $\mathrm{W}$ concentrations of $9 \%$ and $18 \%$, respectively. The $9 \% \mathrm{~W}$ containing sample contains small crystallites $(5-10 \mathrm{~nm})$, homogeneously distributed. In the $18 \% \mathrm{~W}$ containing sample a broad distribution of crystallite sizes is observed $(10-200 \mathrm{~nm})$, with decreasing average size with increasing distance to the surface. However, no explanation for this effect was found yet. Comparing figures $4 a$ ) and $4 b$ ), the crystallite size increases with W concentration. Comparing crystallite sizes in figure 4a) with crystallite sizes in figure 2a) also shows that crystallite size coarsen strongly with temperature.

Performing nano diffraction on a $9 \% \mathrm{~W}$ containing sample annealed to $2800 \mathrm{~K}$ showed that results are comparable to XRD measurements. Nano diffraction allows phase identification of single crystallites on a nm-scale. The analysis of the $9 \%$ a-C:W film annealed to $1450 \mathrm{~K}$ showed that phase analysis is possible even for very small particles using nano diffraction, where XRD fails. Further on, phase mixtures could be identified at $1450 \mathrm{~K}$, which also lead to broad peaks in the X-ray diffractograms. Statistically verified statements will be possible after increasing the analysed number of crystallites. This may give an idea about the fraction of phases inside a sample. Applying statistics it could be learned, whether a mixture of three phases could be found and whether large and medium sized crystallites always lead to the WC phase. 


\section{Summary and Conclusion}

Tungsten carbide phases were analysed in amorphous carbon films containing less than $25 \% \mathrm{~W}$. They were produced by magnetron sputter deposition and annealed to different temperatures up to $2800 \mathrm{~K}$. With increasing temperature, it was possible to form carbide phases, which are forbidden in thermodynamic equilibrium. Atomar dispersed W inclusions inside an amorphous carbon matrix formed nm-sized crystallites. Annealing the $9 \%$ and the $18 \%$ Wcontaining specimen to $2200 \mathrm{~K}$ shows the most impressive dependence on temperature and concentration: The $9 \% \mathrm{~W}$ containing specimen is dominated by $\mathrm{WC}_{1-\mathrm{x}}$ with may be a small fraction of $\mathrm{W}_{2} \mathrm{C}$, while the $18 \% \mathrm{~W}$ starts to be dominated by WC above $\mathrm{W}_{2} \mathrm{C}$. However, at $1450 \mathrm{~K} \mathrm{~W}_{2} \mathrm{C}$ dominates definitely. At temperatures around 2800 $\mathrm{K}$, W inclusions finally tended to crystallize in the WC phase for all concentrations. Crystallite sizes up to $1 \mu \mathrm{m}$ were observed.

\section{Acknowledgements}

P.A. Sauter is grateful to M. Balden for performing XRD measurements and Cross-section

SEM, S. Jong for specimen preparation and heating, F. Koch for maintenance, C. Adelhelm and S. Lindig for inspiration, M. Rasinski and T. Plocinski for performing STEM and nano diffraction. 


\section{References}

[1] J. Roth et al., J. Nucl. Mater. 390-391 (2009) 1 - 9.

[2] C. H. Skinner and G. Federici, Phys. Scr. T124 (2006) 18-22.

[3] C. Adelhelm, PhD Thesis, Technical University Munich, Germany, 2008.

[4] H. Okamoto, J. Phase Equilib. Diffus. 29 (2008) 543-544.

[5] S.V. Prasad et al., J. Appl. Phys. 82(2) (1995) 855-858.

[6] W.J. Meng and B.A. Gillispie, J. Appl. Phys. 84(8) (1998) 4314-4321.

[7] M. Stüber et al., Surf. Coat. Technol. 150(2-3) (2002) 218 - 226.

[8] D. Nilsson et al., Wear, 54(11) (2003) $1084-1091$.

[9] Y.T. Pei et al., Acta Mater. 53(17) (2005) 4505 - 4521.

[10] Al. Mrabet et al., Plasma Process. Polym., 6 (2009) S444 - S449.

[11] M. D. Abad, J. Appl. Phys. 105(3) (2009) 105-110.

[12] O.Wilhelmsson et al., J. Appl. Phys. 100(5) (2006) 054303-10.

[13] Joined Committee for Powder Diffraction Studies - International Centre for Diffraction Data (JCPDS ICDD), Powder Diffraction File, Release 2000.

[14] M. Birkholz, Thin Film Analysis by X-Ray Scattering, Wiley-VCH, Weinheim, 2006. 


\section{Figure captions}

\section{Fig. 1):}

X-ray diffractograms of annealing series of a-C:W films. W concentration: a) 9\%, b) 18\%, c) $22 \%$. Diffraction peaks for the carbide phases $\mathrm{WC}_{2} \mathrm{~W}_{2} \mathrm{C}, \mathrm{WC}_{1-\mathrm{x}}(\mathrm{PDF}$ card $25-1047,35-$ 776, 20-1316), for $\mathrm{WO}_{3}$ (PDF card 20-1324) and for pure graphite (substrate) are indicated (right axes show the intensity in \% of the PDF data). All films are deposited on graphite substrate. The initial specimen containing $22 \% \mathrm{~W}$ was deposited on a silicon (100) wafer. The small peaks at $62^{\circ}$ and $82^{\circ}$ are artefacts of the signal, created by the silicon substrate.

\section{Fig. 2):}

a) SEM bright field micrograph of a cross-section of a $9 \%$ a-C:W sample, annealed up to 2800 K. b) STEM bright field of a single crystallite (dark area). c) and d) Nano diffraction of single particles revealed the $\mathrm{WC}$ phase and the $\mathrm{WC}_{1-\mathrm{x}}$ phase, respectively. Note $\mathrm{d}$ ) is made on the crystallite in the central of $b$ ).

\section{Fig. 3):}

a) STEM bright field micrograph of a $9 \%$ a-C:W sample, annealed up to $1450 \mathrm{~K}$. b) Magnifacation to nm-scale (overlayer in the upper right corner: correlated STEM Z contrast micrograph). Nano diffraction of single particles revealed c) the $\mathrm{WC}_{1-\mathrm{x}}$ phase and $\mathrm{d}$ ) the $\mathrm{W}_{2} \mathrm{C}$ phase (area of diffraction: about $3 \times 3 \mathrm{~nm}^{2}$ ). 
Fig. 4):

Cross-section SEM of a-C:W samples annealed to $2200 \mathrm{~K}$. a) $9 \%$ W-content, small crystallite sizes. b) $18 \% \mathrm{~W}$-content, bimodal distribution of crystallite sizes (sizes increasing towards the surface). 


\section{figures}

Fig. 1)
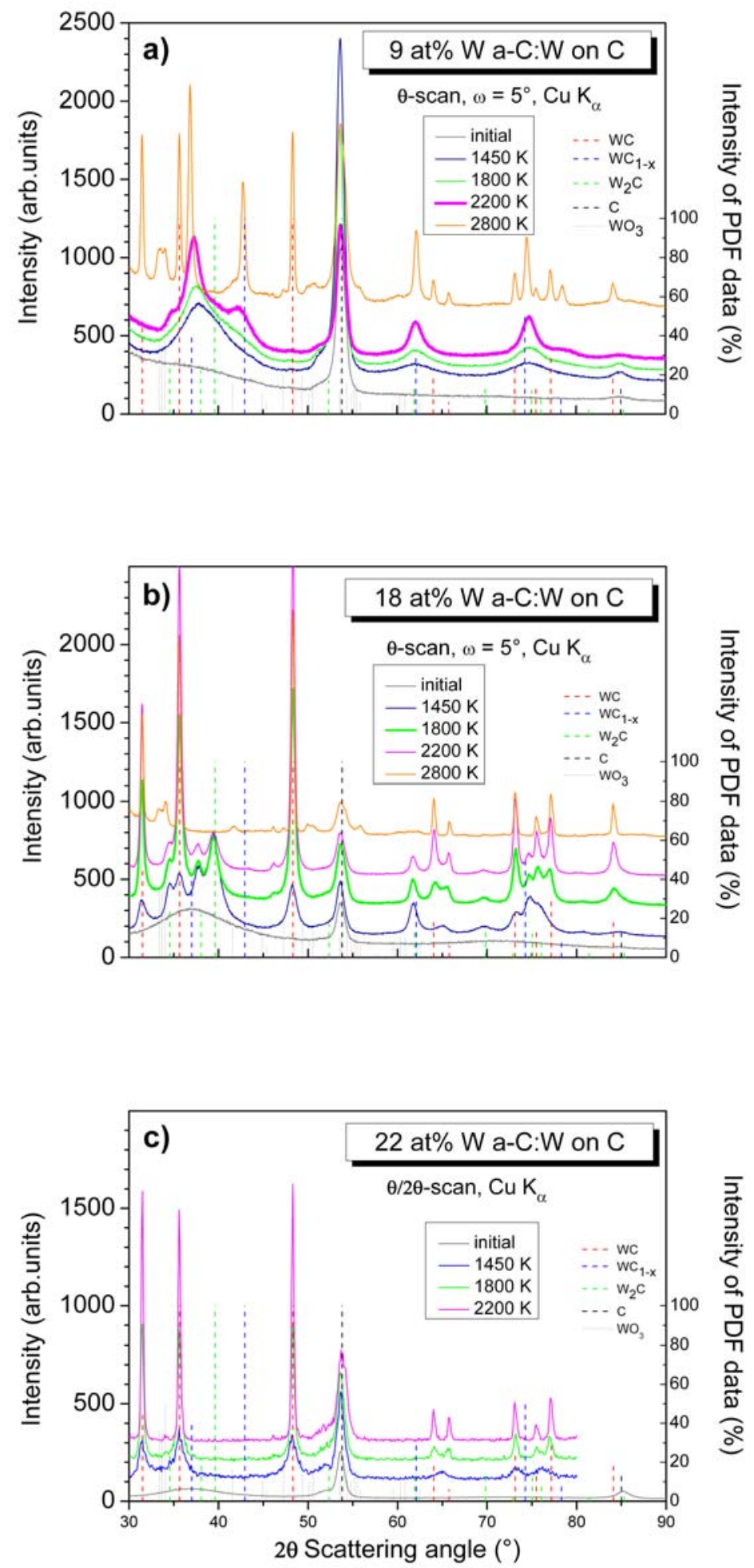
Fig. 2)

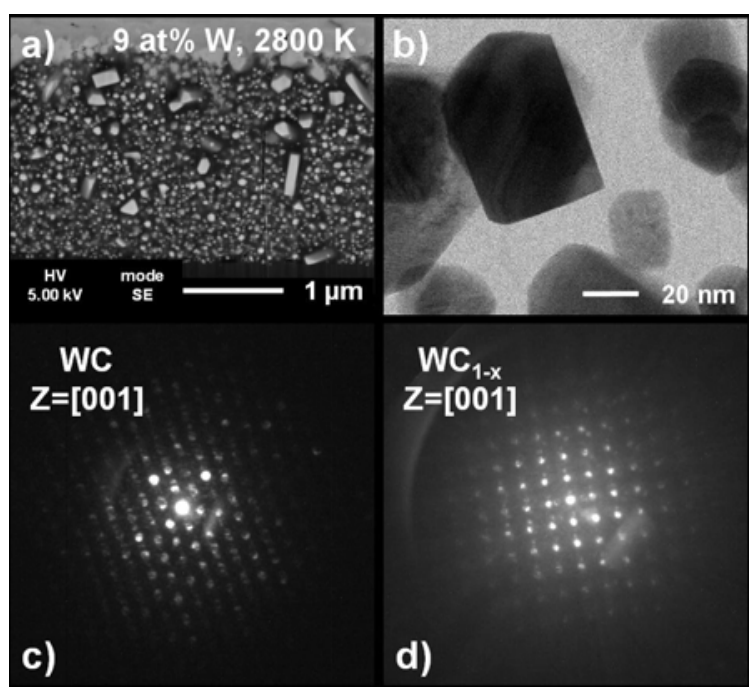

Fig.3)

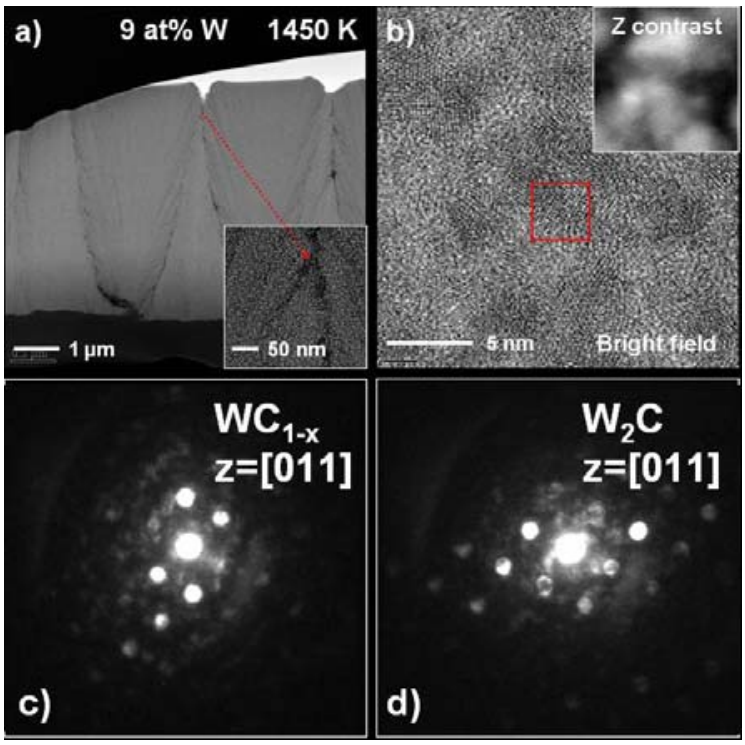

Fig. 4)

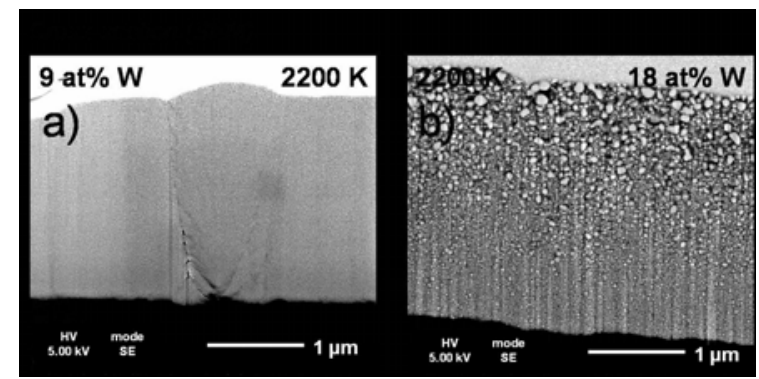

